\title{
Análise microscópica do miocárdio ventricular esquerdo em cães soropositivos para cinomose ${ }^{1}$
}

\author{
Rodrigo S. de Rezende ${ }^{2,3 *}$, Humberto E. Coelho ${ }^{3}$, Regis Kamimura ${ }^{3}$, Renato \\ S. Severino ${ }^{4}$, Pedro C.L. de Oliveira ${ }^{3}$, Alessandra A. Medeiros ${ }^{3}$ e Aline O.C. \\ Magalhães ${ }^{5}$
}

\begin{abstract}
Rezende R.S., Coelho H.E, Kamimura R., Severino R.S, Oliveira, P.C.L., Medeiros A.A. \& Magalhães A.O.C. 2009. [Microscopic analysis of the left ventricular myocardium in positive serum dogs to distemper disease.] Análise microscópica do miocárdio ventricular esquerdo em cães soropositivos para cinomose. Pesquisa Veterinária Brasileira 29(2):117-119. Instituto de Estudos Avançados em Veterinária José Caetano Borges, Universidade de Uberaba, Av. do Tutunas 720, Uberaba, MG 38061500, Brazil. E-mail: rezendehvu@hotmail.com

Classified pertaining to the genus Morbillivirus of the Paramyxoviridae family, the canine distemper virus is a RNA single-stranded virus with negative polarity and causes a multisystemic disease, serious and highly contagious for dogs and wild carnivores, with a high mortality rate in non-vaccinated animals or with vaccine fails. With the objective to evaluate heart histopathological alterations, particularly in the left ventricular myocardium, in dogs naturally infected with canine distemper virus, 35 dogs, males and females of different ages, were studied. All the 35 samples sent to the Veterinary Hospital of Uberaba were serum-positive for distemper (immunoassay technique in solid phase) and had in the left ventricular myocardium the following histopathologic alterations: myocarditis, hyalin degeneration, hyperemia and hemorrhage, in $42.8 \%$ (15/35), 31.4\% (11/35), 14.3\% (5/35) and 11.4\% (4/35), respectively. Having carried out the Qui-Quadrado test with a significancy level of 0.05 , it can be concluded that there is a high correlation $(p=0.02)$ between the infected animals with canine distemper virus and histopathological alterations found in the left ventricular myocardium.
\end{abstract}

INDEX TERMS: Distemper, myocarditis, immunoassay, dog.

RESUMO.- Classificado no gênero Morbillivirus da família Paramixoviridae, o vírus da cinomose possui RNA de fita simples de polaridade negativa, é causador de doença multissistêmica, altamente contagiosa e grave dos cães e carnívoros selvagens, e com elevado índice de mortalidade em animais não vacinados ou com falhas vacinais. Com

\footnotetext{
${ }^{1}$ Recebido em 8 de outubro de 2007.

Aceito para publicação em 22 de setembro de 2008.

2 Pós-Graduando em Ciências Veterinárias, Faculdade de Medicina Veterinária, Universidade Federal de Uberlândia (UFU).

${ }^{3}$ Instituto de Estudos Avançados em Veterinária José Caetano Borges, UFU, Av. do Tutunas 720, Uberaba, MG 38061-500, Brasil. *Autor para correspondência: rezendehvu@hotmail.com

${ }^{4}$ Faculdade de Medicina Veterinária, UFU, Rua Ceará s/n, Bloco 2T, Jardim Umuarama, Uberlândia, MG 38400-902, Brasil.

${ }^{5}$ Pós-Graduanda em Ciências Veterinárias, Faculdade de Medina Veterinária, UFU, Uberlândia, MG.
}

o objetivo de avaliar as alterações histopatológicas no coração, particularmente na região do miocárdio ventricular esquerdo, de cães naturalmente infectados com o vírus da cinomose, foram estudados 35 animais, de ambos os sexos e com idades variadas. Das 35 amostras enviadas ao Laboratório de Medicina Veterinária Preventiva do Hospital Veterinário de Uberaba, 100\% (35/35) mostrou-se soropositivas para a cinomose (técnica de imunoensaio em fase sólida) e tiveram no miocárdio ventricular esquerdo as seguintes alterações histopatológicas: miocardite, degeneração hialina, hiperemia e hemorragia, com 42,8\% (15/ $35), 31,4 \%$ (11/35), 14,3\% (5/35) e 11,4\% (4/35), respectivamente. Tendo utilizado o teste Qui-Quadrado com nível de significância de 0,05 , conclui-se que existe alta correlação $(p=0,02)$ entre os animais infectados com o vírus da cinomose e as alterações histopatológicas observadas no miocárdio ventricular esquerdo. 
TERMOS DE INDEXAÇÃO: Cinomose, miocardite, imunoensaio, cão.

\section{INTRODUÇÃO}

A cinomose é uma doença viral multissistêmica, altamente contagiosa e grave dos cães e carnívoros selvagens, sendo observada mundialmente (Headley \& Graça 2000, Moritz et al. 2000, Willis 2002). Na primeira metade do século $X X$, a cinomose foi uma das doenças fatais mais comuns em cães em todo o mundo. Posteriormente, a partir dos anos 60 e com o surgimento de vacinas específicas, este quadro modificou-se. Atualmente, a mortalidade ainda é comum em animais não vacinados ou naqueles imunizados em que se observa qualquer problema de falha vacinal (Appel \& Summers 1999).

$O$ vírus da cinomose canina, pertence ao gênero Morbillivirus da família Paramixoviridae possui RNA de fita simples com polaridade negativa (Van Regenmortel et al. 2000). Uma das características desta infecção é a formação de corpúsculos de inclusão eosinofílicos, denominados de corpúsculos de Lentz, que podem ser intranucleares ou intracitoplasmáticos, e que são encontrados em vários tecidos além do sistema nervoso central, como nas células epiteliais da bexiga urinária e do trato respiratório (Beer 1998).

Existe apenas um sorotipo do vírus da cinomose, no entanto, há cepas biologicamente diferentes. Algumas são levemente virulentas e comumente causam infecções inaparentes, outras levam a manifestação da doença aguda, com elevada freqüência de encefalite e mortalidade alta. Existem também cepas mais viscerotrópicas, que geram uma enfermidade debilitante com mortalidade elevada, mas com baixa freqüência de encefalite (Headley \& Graça 2000, Moritz et al. 2000, Willis 2002).

Os sinais clínicos da cinomose canina podem variar de acordo com a virulência da estirpe viral infectante, o estado imunológico e com a idade dos cães. Com maior freqüência são observadas alterações oculares, respiratórias, gastrointestinais, cardíacas e neurológicas. Esses sinais podem, isoladamente ou em associação, serem encontrados em outras doenças infecciosas, dificultando o diagnóstico clínico (Rude 1987, Shell 1990, Tipold 1995, Higgings et al 1981).

Acredita-se que as viroses cardiotrópicas desempenham importante papel na patogenia da miocardite em várias espécies, geralmente como resultado de infecção hematógena do miocárdio, podendo ocorrer assim em várias doenças sistêmicas (Van Valeet \& Ferrans 1998), inclusive na infecção pelo vírus da cinomose.

A evolução das miocardites pode incluir: completa resolução das lesões, cicatrizes miocárdicas residuais esparsas ou lesão miocárdica progressiva com insuficiência cardíaca aguda, ou ainda, em alguns casos crônicos, como cardiomiopatia dilatada secundária. Torna-se, portanto, importante o conhecimento de sua etiologia e da patogenia que desencadeia a miocardite e, consequentemente, a dilatação cardíaca com insuficiência, para que se estabeleça um correto tratamento (Robinson \& Maxie 1993).
O objetivo do presente trabalho foi avaliar as alterações histopatológicas na região do miocárdio ventricular esquerdo, de cães naturalmente infectados com o vírus da cinomose, diagnosticados sorologicamente pelo Laboratório de Medicina Veterinária Preventiva do Hospital Veterinário de Uberaba, no período de janeiro a agosto de 2007.

\section{MATERIAL E MÉTODOS}

Animais. Foram utilizados 35 cães sem raça definida (SRD), de ambos os sexos e com idades variadas, sorologicamente positivos para cinomose. Os cães foram atendidos no Hospital Veterinário de Uberaba e vieram a óbito por evolução da doença no período de janeiro a agosto de 2007, apresentando sintomas neurológicos.

Preparação das lâminas. Os animais foram necropsiados no Laboratório de Patologia Animal da Universidade de Uberaba, onde foram coletados fragmentos do miocárdio ventricular esquerdo para exames histopatológicos. As amostras foram fixadas em formol a $10 \%$ e processadas conforme rotina de preparação de lâminas histológicas: desidratadas em álcoois, diafanizadas em xilol, incluídas em parafina histológica, cortadas a cinco micrômetros de espessura, coradas pela hematoxilina eosina (HE) e examinadas à luz da microscopia óptica.

Teste sorológico. A técnica utilizada para a detecção de anticorpos da classe lgG específicos para o vírus da cinomose canina no soro, é baseada no princípio imunoenzimático em fase sólida, e para isto utilizou-se o "antigen rapid CDV Ag test kit" (Bioeasy), seguindo as orientações fornecidas pelo fabricante.

Avaliação estatística. Utilizou-se o teste Qui-Quadrado (Zar 1992) por meio do programa estatístico Bio Estat 4.0 com nível de significância de 0,05 , para verificar a associação entre o diagnóstico positivo para cinomose e a existência ou não de lesão tecidual no fragmento do miocárdio ventricular esquerdo estudado.

\section{RESULTADOS E DISCUSSÃO}

Todos os cães deste experimento apresentaram alterações neurológicas provocadas pelo vírus da cinomose, o que foi confirmado sorologicamente por $100 \%$ de reações positivas. Resultados semelhantes foram encontrados por Headley \& Graça (2000), que afirmam que as maiores porcentagens de reações positivas em testes sorológicos são encontradas em grupos de animais que apresentam sintomas neurológicos.

A inflamação linfocitária foi a principal alteração encontrada (42,8\%), a qual é sugestiva de resposta imunitária induzida pelo vírus da cinomose, conforme relatam Higgins et al. (1981), Lenghaus \& Studdert (1984), Ettinger (1992) e Rocha (1995). A degeneração hialina é relatada como achado concomitante às alterações inflamatórias no miocárdio (Quadro 1), o que pode ser comprovado estatisticamente no presente estudo $(p=0,02)$, com valores de $31,4 \%$ e $42,8 \%$, respectivamente (Ettinger 1992).

Em 15 dos 35 animais (42,8\%) notou-se a miocardite linfocitária (Fig.1), com freqüência maior do que a encontrada em estudo realizado no Rio Grande do Sul, onde 250 cães submetidos à necropsia, $29(11,70 \%)$ apresentavam lesões miocárdicas inflamatórias. Tal resultado 


\section{Quadro 1. Exame histopatológico do miocárdio ventricular esquerdo em cães soropositivos para cinomose}

\begin{tabular}{lcc}
\hline \multicolumn{1}{c}{ Diagnóstico } & Número de animais & $\%$ \\
\hline Miocardite & 15 & 42,8 \\
Degeneração hialina & 11 & 31,4 \\
Hiperemia & 5 & 14,3 \\
Hemorragia & 4 & 11,4 \\
Total & 35 & 100 \\
\hline
\end{tabular}

Teste do Qui-Quadrado: $p=0,02$.

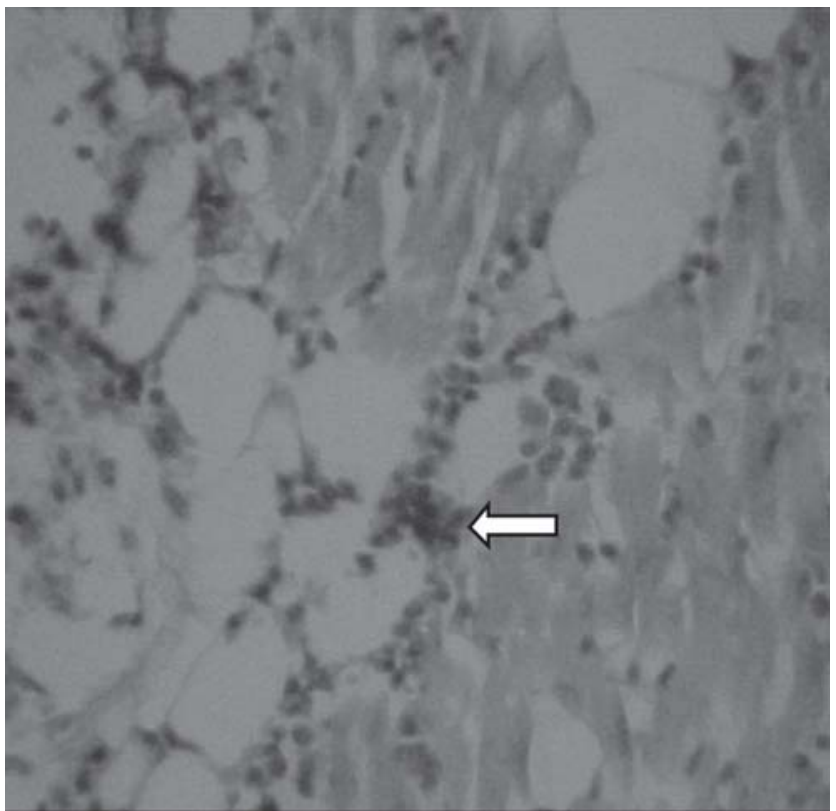

Fig.1. Miocardite focal linfocitária (seta) e infiltração gordurosa do ventrículo esquerdo, de cão SRD com cinomose. HE, obj.10x.

pode ser devido à utilização de animais no experimento sem manifestação nervosa (Headley \& Graça 2000).

Em 31 cães com dilatação cardíaca e soropositivos para a cinomose, foram encontradas as seguintes alterações histológicas no nó sinoatrial: infiltração linfocitária $(45,2 \%)$, degeneração hialina $(26,1 \%)$ e hemorragia $(7,1 \%)$, resultados estes bem próximos aos dos observados na presente investigação (Bastos 2001).

Observa-se, apesar de ser estatisticamente significativa $(p=0,02)$, uma discrepância do número de miocardites em relação aos de hemorragia e hiperemia, este fato, explica-se pelo tempo da instalação do processo, ou seja, a hemorragia e a hiperemia acontecem agudamente e são logo absorvidas pelo tecido adjacente, enquanto que a inflamação persiste por um tempo superior, até tornar-se crônica. As hemorragias que ocorrem no miocárdio são do tipo intersticial, e com etiologias relacionadas à toxemia, septicemia, e viremias (Coelho 2002).

\section{CONCLUSÕES}

Constatou-se, através deste estudo, que existe uma correlação positiva entre cães infectados com o vírus da cinomose e as alterações histopatológicas observadas no miocárdio ventricular esquerdo. Nesse sentido, reforçase a importância da vacinação contínua de cães jovens, reduzindo assim a circulação desse vírus e, consequentemente, a ocorrência da enfermidade e seqüelas cardíacas futuras.

\section{REFERÊNCIAS}

Appel M.J.G \& Summers B.A. 1999. Canine distemper current status, p.30-36. In: Carmichael L.E. (Ed.), Recent Advances in Canine Infectious Disease. International Veterinary Information Service, Ithaca, NY.

Bastos J.E.D. 2001. Alterações do nó sinoatrial em cães com dilatação cardíaca. Dissertação de Mestrado em Clínica e Cirurgia, Faculdade de Medicina Veterinária, Universidade Federal de Uberlândia, MG. 20p.

Beer J. 1998. Doenças Infecciosas em Animais Domésticos. Roca, São Paulo. 457p.

Coelho H.E. 2002. Patologia Veterinária. Manole, São Paulo. 234p.

Ettinger S.J. 1992. Tratado de Medicina Interna Veterinária. Manole, São Paulo. 556p.

Headley S.A. \& Graça D.L. 2000. Canine distemper: Epidemiological findings of 250 cases. Braz. J. Vet. Res. Anim. Sci. 37:52-58.

Higgins R.J., Krakowka S., Metzler A.E. \& Koestner A. 1981. Canine distemper virus-associated cardiac necrosis in the dog. Vet. Pathol. 18:472-486.

Lenghaus C. \& Studdert M.J. 1984. Animal model human disease: Acute and chronic viral myocarditis. Am. J. Pathol. 115:316-319.

Moritz A., Frisk A.L. \& Baumgartner W. 2000. The evaluation of diagnostic procedures for the detection of canine distemper virus infection. Eur. J. Comp. Anim. Pract. 10:37- 47.

Robinson W.F. \& Maxie M.G. 1993. The cardiovascular system p.1100. In: Goldston R.T. \& Hoskins J.D. (Ed.), Pathology of Domestic Animals. $4^{\text {th }}$ ed. Academic Press, San Diego.

Rocha A. 1995. Miocardite chagásica em humanos. Revta Soc. Bras. Med. Trop., Uberlândia, 26:243-249.

Rude T.A. 1987. Canine distemper virus: infection and prevention. Can. Pract. 14:16-24.

Shell L.G. 1990. Canine distemper. Comp. Small Anim.13:173-179.

Tipold A. 1995. Diagnosis of inflammatory and infectious diseases of the central nervous system in dogs: a retrospective study. J. Vet. Int. Med. 9:304-314.

Van Regenmortel M.H.V., Fauquet C.M. \& Bishop D.H.L. 2000. Virus taxonomy: The classification and nomenclature of viruses. Report of the International Committee on Taxonomy of Viruses, Academic Press, San Diego. 1167p.

Van Valeet J.F. \& Ferrans V.J. 1998. Patologia do sistema cardiovascular, p.194-227. In: Brinker W.O., Piermatei D.L. \& Flo G.L. (Ed.), Patologia Veterinária Especial. 2ª ed. Manole, São Paulo.

Willis A.M. 2002. Infections disease and the eye: canine viral infections. Vet. Clin. North Am., Small Anim.Pract. 30:1119-1134.

Zar J.H. 1992. Biostatistical Analysis. $4^{\text {th }}$ ed. Trenton, New Jersey. p.100110. 